life (a concept they call "'speciesism') and support their case by quoting the acceptance of post-coital contraception such as the use of IUDs in modern society.

Carey considers informed consent in relation to the Nuremburg Code, the Declaration of Helsinki and earlier debates on the right of an embryo to give consent to its own beginnings. Discussions on the rights of embryos to consent have always seemed to me to be astonishingly devious, as if embryos can be or are ever asked anything a: all, and I was delighted that in his contribution Carey agrees by quoting Fletcher's " $N$.ads are the moral stabilisers, not rights". Carey, however, sadly passes over one of the most difficult questions: how can parents realistically consent to the use of an embryo for research without making massive decisions about embryonic rights? Surely parents can consent only to therapeutic treatments on an embryo; when used for research it is bound to succumb, and parental consent for this implies that the embryo is their material possession, without any right to its own life.

In later chapters of the book, Daniel and Morgan accept the desire of childless couples for children, and stress that the patients are not depersonalized by the procedure. I have long suspected arguments that conception in vivo expresses "love", whereas fertilization in vitro debases it. The loving demands of infertile couples, one to the other, during fertilization in vitro can be far greater than during a chance sexual act leading to conception. I also appreciated Henley's argument, that the small size of the pre-implantation embryo has little relation to any judgement of its "humanness". Rassaby emerges as very liberal and sympathetic on the surrogate mother, a somewhat unusual ethical stance, and Walters braces up to a difficult assignment on cloning, etc., concluding by condemning any potential studies on mananimal hybrids. I fully agree with him.

Some fundamentals of ethical debate are conspicuously absent from this book, many of them concerned with the science and medicine of human conception. Repetition of the absolutist case of the "camel's nose" argument must simply be rejected: undesirable ends are avoided in many areas of human life and can also be avoided with conception in vitro. Many aspects of early human embryology also add support to the rejection of absolutism: the genotype of a surprisingly large number of embryos is not finally established at fertilization - as Hassold has recently reminded us with reference to mosaic trisomies - and no one could give any value to an androgenetic embryo destined to result in a molar and perhaps cancerous pregnancy. Worse, however, is a lack in this book of the details of the enormous potential for good in studying early embryos - identifying those with genetic defects, studying differentiation and normal and abnormal growth, teratogenesis, aspects of cancer, even the use of embryonic stem cells in medicine - the list is almost endless. The enormous research potential for science and medicine, and consequent benefits for ameliorating mental and physical suffering, is for me decisive in debates on the ethical dilemma. The question of children conceived in vitro involves one set of ethical issues; the rights or otherwise of embryos in vitro raises quite different arguments about the value of research in relation to ethics.

A conflict arises for many of us in contemplating these research studies. Human life must be accepted ethically as being different from animal life - I cannot accept Kuhse and Singer's "speciesism" charge. Equally, we cannot use the small size of a pre-implantation embryo as a moral arbiter, or accept excuses that embryos can be used for research because they would not be there but for in vitro fertilization. The fact that some women wear IUDs does not allow us to evade our personal ethical decisions. Nor do concepts such as pain, rationality and consciousness really help in solving our ethical problems on the early embryo, because such parameters take us far into fetal life - weeks, months or even years after fertilization. Such concepts are unhelpful and misleading. The conflict is worst for those who regard a human embryo as different to, say, a mouse embryo, yet accept the need for embryonic research to alleviate disastrous conditions in children or adults. How can notions such as "respect" or "dignity" for an embryo be applied when it will be used for such a need? Decisions about research are made easily by those who believe the embryo has no rights at all, but not by those with reservations.

There is one other significant omission in this book. Where do we find the viewpoints of the Australian scientists and doctors actually involved in the work? They are in the front line - developing the techniques and as a consequence undeniably enmeshed in the ethics. Walters, the co-editor is a gynaecologist, but evidently not involved in the field directly. After their "state of the art" message, the participants in in vitro fertilization leave almost all of the ensuing debate to theologians, ethicists and philosophers. How do such practitioners answer Archbishop Little's question in the book: how they gained "the moral right to embark on a procedure which placed them in the predicament of 'destruction or freezing'." Surely, those most clearly involved should have something to contribute, something others cannot? Such inertia inevitably leads to gibes such as "What can be done will be done", and the implication of an uncaring, unfeeling science is reinforced. Research workers must clarify the issues in debate, publicize their ethical attitudes and justify their work to avoid such implications.

R.G. Edwards, a pioneer in the techniques of in vitro fertilization, is Reader in Physiology at the University of Cambridge.

\section{Talk of DNA}

\section{F. J. Bollum}

Man Made Life: A Genetic Engineering

Primer.

By Jeremy Cherfas

Basil Blackwell/Pantheon: 1982. Pp.270.

Hbk £16, \$15.95; pbk £5.50, \$7.95.

Scientists and non-scientists will be attracted by the title of this book; the subtitle should extend the readership to precocious kindergarteners anticipating the arrival of their first cloning kit from the local molecular biology company. Despite the banner headlines Jeremy Cherfas's appeal to this wide audience will probably depend on individual tastes.

The book presents the cosmos of genetic engineering, beginning with the discovery of DNA structure and the tools required for manipulation of DNA molecules. General procedures for cloning and DNA sequencing are covered, bringing the reader right up to the question of what monster he might like to make. As a word of caution, the social eruption resulting from the regulatory discussions of the mid-1970s is introduced, and then it's back to the coli shakers.

Benefits to mankind in the production of rare and important hormones and difficult vaccines, and other biotechnology issues, fill the next three chapters. Benefits received by certain individuals in the form of capital gains are also included for conversational interest. Finally, re thinking the scientific problems already opened wide by recombinant DNA experiments and an outlook for the future brings us to the final page. But who will be there at the end?

Although I believe that recombinant DNA technology is a serious and interesting subject, I had great difficulty getting through this book, perhaps because of the unusual writing style. The story might be performed convincingly on the BBC, but it does not read well. Cherfas's penchant for writing letters to famous scientists and then referencing his own correspondence as documentation of some trivial idea is more irritation than supplementation.

Then there is the choice of subjects for discourse. The author tends to select those topics that he thinks are important because he heard of them from famous scientists. An example is the discussion of restriction enzymes in Chaper 2. While scientific drones may be interested in the general subject of restriction and Type I restriction enzymes, those baby cloners are not. They

\section{Price of Red Deer}

In last week's Nature (p.734) the hardback dollar price was omitted in the review of T.H. Clutton-Brock et al.'s Red Deer: Behaviour and Ecology of Two Sexes. Full prices are hbk $£ 20$, $\$ 30$; pbk £9.75, \$12.95. 
want the bottom line - Type II restriction enzymes. Somewhat surprisingly other enzymes are sort of ho-hummed, even though a famous scientist reminded Cherfas that those enzymes are important. Clearly the author is not to be deterred by this kind of fact - he prefers conversation.

Speaking of important facts, there is the description of the preparation of a recombinant phage library (p.113):

Once the phage had grown and amplified their precious cargo several hundred times, the agar was scraped off the plates and mixed with a little chloroform to ensure that the cells that had not yet burst to release their phage would do so. The whole lot, about one third of a litre, was spun in a centrifuge to remove bits of agar and cell debris, and popped into the freezer for storage: a small jar, holding the entire human genome as a collection of handy, ready to use pieces.

It was prose like this that caused me to fail Freshman English composition. And, continuing his interpretation at the undergraduate level of understanding, we find (p.51) that DNA electrophoresis on agarose was a major scientific advance because it avoided adjusting solvent concentrations of column fractions obtained during enzyme purification. And to validate the importance of this last breakthrough we have a direct quotation from a letter to Cherfas (p.52), to wit:
'Agarose gel electrophoresis did not originate with our Biochemistry paper', Sharp has told me, 'but was certainly popularized by it.'

There is a lot of silly conversation in this book, and terms such as Frederick's ladder and Walter's cookbook are not the silliest.

One might also question some of the value judgements. There are several references to the tedium of protein purification, and on p.145 we learn that because of genetic engineering of DNA ligase genes "the tedium of protein purification became much more worthwhile. . .". Aside from the questionable logic, I imagine that those who purify proteins find it a rather stimulating and useful occupation.

I would guess that my reaction is partly cultural, since Americans expect citizens of Great Britain to write and speak in good English, often mistaking a clipped accent for a sign of intelligence. In the present instance the familiar presentation of questionable facts may make this book popular with academic camp followers, but our new generation cloners and budding venture capitalists will probably look elsewhere for the hard facts of recombinant DNA technology.

F.J. Bollum is a Professor of Biochemistry at the USUHS, Bethesda, Maryland.

\section{Darwinian delicacies}

\section{Colin Patterson}

\section{Hen's Teeth and Horse's Toes: Further \\ Reflections in Natural History.}

By Stephen Jay Gould.

W.W. Norton: 1983. Pp.413. \$15.50.

REVIEWING Stephen Gould's essays, I was tempted to begin, as he so often does, with a snatch of libretto or a quote from a favourite sage. But I resist the temptation; as with top-class cooking, it may be easy to identify ingredients, but what is put on the table has been transformed in an inimitable way.

Hen's Teeth and Horse's Toes is Gould's third collection of essays, following Ever Since Darwin (1977) and The Panda's Thumb (1980). As before, almost all of the pieces first appeared in Natural History, the monthly published by the American Museum of Natural History. Two of the thirty essays are from other sources, a trifle on the evolution of Hershey bars, and one of a trio on the creationist revival. There is one new piece, a reply to critics of Gould's thesis that Teilhard was in on the game at Piltdown.

Gould's themes range from the topical (sociobiology, creationism, a terminal Cretaceous asteroid impact), through the historical (Cuvier, Agassiz, Vavilov), to the timeless "is Darwinism enough?". Evolutionary theory is his concern in most of these essays, and he comes at it from all sides. Gould's own answer to the question about Darwinism is "no". He advocates a pluralistic and hierarchical theory, with junk DNA and neutralism active at the molecular level, neo-Darwinism at the intraspecific level and as the explanation for finely-tuned adaptation, but not for the origin of species or of all novelty. Species may frequently arise by chance events, and randomly generated species form the raw material of species selection, a process analogous to natural selection, but acting at a different hierarchical level. Evolutionary novelties may not be ground out by slow mill of natural selection, but generated instantly by changes in ontogenetic control, like atavism and homeosis. And the box is shaken now and again by random catastrophes such as asteroid impacts or continental collisions.

Whether or not you agree with Gould, you will surely enjoy and admire the vigour of his style, his agile and fertile mind, and his protean scholarship. Who else could spin a couple of thousand entertaining and provocative words from themes as unpromising as the census, or Steno's views on solids within solids? Only one rival comes to mind, T.H. Huxley, who did the same with "Yeast" and "A Piece of Chalk". I don't know how Steve does it, but I hope he keeps it up. Together with his many other fans, I look forward to the fourth collection.

Colin Patterson is Senior Principal Scientific Officer in the Palaeontology Department, British Museum (Natural History), London.
ADVERTISEMENT

\section{New titles from Pitman}

\section{Introduction to}

Immunogenetics

M B Zaleski, S Dubiski, E G Niles,

R K Cunnigham

This self-contained approach deals with three traditional fields of

immunogenetics - immunoglobulins,

blood groups, and cell surface

alloantigens. The information is

presented from three interrelated points

of view - genetic, structural and

functional.

Hardback $/ 191 \times 234 \mathrm{~mm} / 496$ pages

May 1983/ISBN 0273019252

Price $£ 18.75$ net

\section{Temperate Legumes:}

Physiology, Genetics and

Nodulation

Edited by D Gareth Jones and

D Roy Davies

Invited papers from a meeting organised by the physiology group of the AAB. The volume will interest plant biologists, plant physiologists, geneticists, microbiologists, agriculturalists and plant breeders.

Hardback $/ 244 \times 172 \mathrm{~mm} / 448$ pages Sept 1983/ISBN 0273086014

Price $£ 15.95$ non net

\section{Functional Ontogeny}

Edited by David McFarland

Starting from basic concepts in

quantitative ethology, leading experts in the field of animal behaviour discuss topics relevant to ontogeny - in particular life history strategies and functional aspects of learning.

Paperback $/ 244 \times 172 \mathrm{~mm} / 256$ pages Sept 1982/ISBN 027308545 X

Price $\mathbf{8 8 . 5 0}$ non net

\section{Brush Border Membranes}

\section{Ciba Foundation Symposium 95}

Brush border membranes are found in the gut, kidney and placenta. This volume focuses on the structure,

molecular organisation and functions of these membranes.

Hardback $/ 299 \times 152 \mathrm{~mm} / 350$ pages April 1983/ISBN $027379659 \mathrm{X}$ Price $£ 25$ net

\section{Fetal Antigens and Cancer} Ciba Foundation Symposium 96

This volume considers evidence that fetal tissues can protect against experimentally induced tumours, and that this protection is immunological and specific in its mechanism.

Hardback $/ 229 \times 152 \mathrm{~mm} / 272$ pages May 1983/ISBN 0272796603

Price £25 net

All prices subject to change without notice. Available from your bookseller, or in case of difficulty from Cashpost Service, Book

Centre, Southport PR9 9YF England. Please enclose remittance with your order and quote the ISBN.

Pitman Books Ltd, 128 Long Acre. London WC2E 9AN England. 